\title{
TU/e EmonOWEN

\section{Quantitative analysis in capillary zone electrophoresis with conductivity and indirect UV detection}

\section{Citation for published version (APA):}

Ackermans, M. T., Everaerts, F. M., \& Beckers, J. L. (1991). Quantitative analysis in capillary zone electrophoresis with conductivity and indirect UV detection. Journal of Chromatography, 549(1-2), 345-355. https://doi.org/10.1016/S0021-9673(00)91445-6

DOI:

10.1016/S0021-9673(00)91445-6

Document status and date:

Published: 01/01/1991

\section{Document Version:}

Publisher's PDF, also known as Version of Record (includes final page, issue and volume numbers)

\section{Please check the document version of this publication:}

- A submitted manuscript is the version of the article upon submission and before peer-review. There can be important differences between the submitted version and the official published version of record. People interested in the research are advised to contact the author for the final version of the publication, or visit the $\mathrm{DOI}$ to the publisher's website.

- The final author version and the galley proof are versions of the publication after peer review.

- The final published version features the final layout of the paper including the volume, issue and page numbers.

Link to publication

\section{General rights}

Copyright and moral rights for the publications made accessible in the public portal are retained by the authors and/or other copyright owners and it is a condition of accessing publications that users recognise and abide by the legal requirements associated with these rights.

- Users may download and print one copy of any publication from the public portal for the purpose of private study or research.

- You may not further distribute the material or use it for any profit-making activity or commercial gain

- You may freely distribute the URL identifying the publication in the public portal.

If the publication is distributed under the terms of Article 25fa of the Dutch Copyright Act, indicated by the "Taverne" license above, please follow below link for the End User Agreement:

www.tue.nl/taverne

Take down policy

If you believe that this document breaches copyright please contact us at:

openaccess@tue.nl

providing details and we will investigate your claim. 


\title{
Quantitative analysis in capillary zone electrophoresis with conductivity and indirect UV detection
}

\author{
M. T. ACKERMANS, F. M. EVERAERTS and J. L. BECKERS* \\ Eindhoven University of Technology, Laboratory of Instrumental Analysis, P.O. Box 513, 5600 MB Eind- \\ hoven (Netherlands)
}

(First received January 26th, 1991; revised manuscript received March 19th, 1991)

\begin{abstract}
An interesting point in quantitative capillary zone electrophoresis, when applying conductivity detection or indirect UV detection with non-UV absorbing components, is the existence of a relationship between effective mobilities and peak area, independent of the kind of ionic species. This relationship is theoretically considered for fully ionized monovalent ions resulting in a linear relationship, passing through the origin, between temporal peak area and the product of a correction factor (dependent only on the effective mobilities of the ionic species) and migration time for an equimolar sample composition. A good correlation between theory and practice could be established by applying experimental measured data.
\end{abstract}

\section{INTRODUCTION}

Huang et al. [1] reported on the unique advantage of quantitative capillary zone electrophoresis (CZE) using conductivity detection that the use of an internal standard allows the accurate determination of absolute concentrations in a mixture without separate calibration of the response for each component and they found a direct relationship between peak area and migration times. Further consideration of the principle of the measured conductivity shows, however, that although a relationship exists between peak area and migration time it is nearly linear only over a small mobility range. In this paper, the relationship between peak area and effective mobility for conductivity and indirect UV detection in CZE is considered for fully ionized monovalent ions.

\section{THEORETICAL}

Assuming only the presence of fully ionized monovalent ionic constituents, the electrophoretic separation mechanism can approximately be described by Kohlrausch's regulation function:

$$
\sum_{i} c_{i} / m_{i}=\omega
$$


where $c_{i}$ and $m_{i}$ represent the ionic concentrations and absolute values of the effective ionic mobilities of all ionic constituents and the numerical value of the Kohlrausch function $\omega$ is locally invariant with time [2]. If a volume element of the capillary is originally filled with a carrier electrolyte $\mathbf{A B}$ (consisting of a co-ion $\mathrm{A}$ and counter ion B) at a concentration $c_{\mathrm{A}}$, it will contain after some time a mixture of sample components and carrier electrolyte when sample components pass, but finally the original situation will be restored again. If a mixture of a component $i$ and the carrier electrolyte $\mathrm{AB}$ passes through such a volume element, the following equation is valid:

$$
c_{\mathrm{A}}^{\mathrm{C}}=c_{\mathrm{A}}^{\mathrm{S}}+c_{\mathrm{i}}^{\mathrm{s}} k_{i}
$$

with

$$
k_{i}=\frac{m_{i}+m_{\mathrm{B}}}{m_{\mathrm{A}}+m_{\mathrm{B}}} \cdot \frac{m_{\mathrm{A}}}{m_{i}}
$$

The superscripts $\mathrm{C}$ and $\mathrm{S}$ refer to the composition of the pure carrier electrolyte $\mathrm{AB}$ zone and the sample zone, respectively. The concentration of the counter ion B is determined by the electroneutrality condition.

For the zone conductivity $\sigma$ can be derived:

$$
\sigma^{s}=\sigma^{\mathrm{c}}+c_{i} b_{i}
$$

where

$$
b_{i}=F\left(m_{i}+m_{\mathrm{B}}\right)\left(1-m_{\mathrm{A}} / m_{i}\right)
$$

Applying a conductivity detector in capillary electrophoresis, a detector response, directly related to $\sigma^{\mathrm{s}}-\sigma^{\mathrm{c}}$, can be expected being linearly proportional to $b_{i} c_{i}$ and hence the spatial [3] peak area will be proportional to the product of $b_{i}$ and the injected amount $Q_{\text {inj. }}$.

Generally, the measured peak area will be expressed on a temporal basis [3] and it can be expected that for CZE both without and with electroosmotic flow (EOF) the measured peak area $A_{i}$ will be proportional to:

$$
b_{i} Q_{\text {inj }} t_{i}
$$

As the migration time $t_{i}$ is reversely proportional to $m_{i}$ and $m_{i}+m_{\mathrm{EOF}}$ (without and with EOF, respectively) at a given voltage the measured peak area $A_{i}$ will be proportional to:

$$
b_{i} Q_{\mathrm{inj}} / m_{i} \text { or } b_{i} Q_{\mathrm{inj}} /\left(m_{i}+m_{\mathrm{EOF}}\right)
$$

The relationship between measured peak area $A_{i}$ and $b_{i} / m_{i}, b_{i} /\left(m_{i}+m_{\mathrm{FOF}}\right)$ or $b_{i} t_{i}$ must be linear, passing through the origin, whereas the products $A_{i} m_{i} / b_{i}, A_{i}\left(m_{i}+\right.$ $\left.m_{\mathrm{EOF}}\right) / b_{i}$ and $A_{i} / b_{i} t_{i}$ should be a constant for all different ionic species for an equimolar sample composition. It must be remembered that generally in chromatographic 


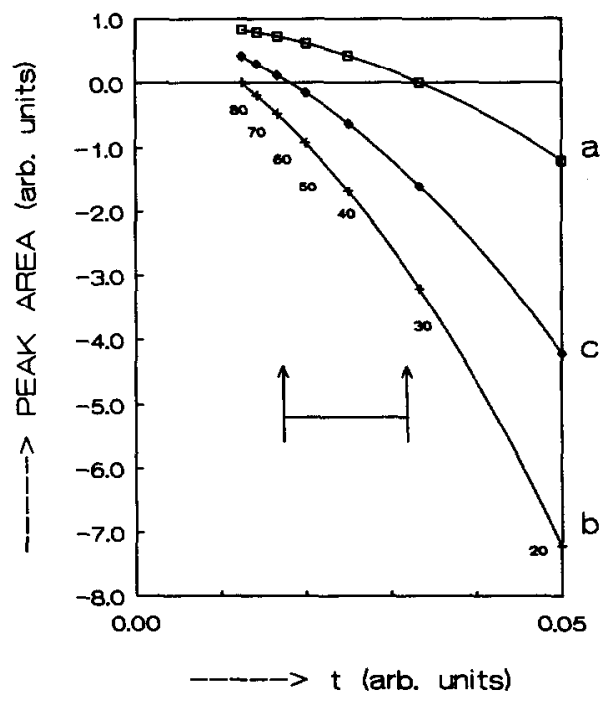

Fig. 1. Calculated relationship between temporal peak area and migration time ( $t$, arbitrary units) for ionic species with effective mobilities of $80 \cdot 10^{-5}$ to $20 \cdot 10^{-5} \mathrm{~cm}^{2} / \mathrm{V} \cdot \mathrm{s}$ assuming effective mobilities for co- and counter ions of (a) $30 \cdot 10^{-5}$ and $30 \cdot 10^{-5}$, (b) $80 \cdot 10^{-5}$ and $30 \cdot 10^{-5}$ and (c) $55 \cdot 10^{-5}$ and $30 \cdot 10^{-5} \mathrm{~cm}^{2} / \mathrm{V}$ - $\mathrm{s}$. The numbers refer to the effective mobilities, $m \cdot 10^{5} \mathrm{~cm}^{2} / \mathrm{V} \cdot \mathrm{s}$, of the ionic species.

techniques one has to work with spatial peak area as the components move with equal speed through the detector.

In Fig. 1 the peak areas (arbitrary units), calculated according to eqn. 5 (without EOF) for a given $Q_{\text {inj }}$, are given as a function of the migration times for ionic species with effective mobilities varying from $80 \cdot 10^{-5}$ to $20 \cdot 10^{-5} \mathrm{~cm}^{2} / \mathrm{V} \cdot \mathrm{s}$ and assuming effective mobilities for $m_{\mathrm{A}}$ and $m_{\mathrm{B}}$ of (a) $30 \cdot 10^{-5}$ and $30 \cdot 10^{-5}$, (b) 80 . $10^{-5}$ and $30 \cdot 10^{-5}$ and (c) $55 \cdot 10^{-5}$ and $30 \cdot 10^{-5} \mathrm{~cm}^{2} / \mathrm{V} \cdot \mathrm{s}$. It can be clearly seen from Fig. 1 that the peak area changes sign at a mobility $m_{i}$ equal to $m_{\mathrm{A}}$ and increases with larger differences between $m_{i}$ and $m_{\mathrm{A}}$. Further, the relationship is not linear,

\section{TABLE I}

MEASURED PEAK AREAS $A_{i}$ (ARBITRARY UNITS), MIGRATION TIMES $t_{i}$ (s) AND RATIOS $c_{i} / c_{s t}$ CALCULATED WITH THE EQUATION ACCORDING TO REF. 1

Carrier electrolyte: (I) $0.01 M$ MES-histidine at pH 6; (II) $0.005 M$ chloride-Tris at $\mathrm{pH} 7.1$

\begin{tabular}{|c|c|c|c|c|c|c|}
\hline \multirow[t]{2}{*}{ Ionic species } & \multicolumn{3}{|l|}{ I } & \multicolumn{3}{|l|}{ II } \\
\hline & $A_{i}$ & $t_{\mathrm{i}}$ & $c_{i} / c_{\mathbf{s t}}$ & $A_{i}$ & $t_{i}$ & $c_{l} / c_{\mathrm{st}}$ \\
\hline Formate & 53.1 & 113 & 1.83 & 10.5 & 280 & 0.14 \\
\hline Acetate & 37.0 & 148 & 1.67 & 26.7 & 338 & 0.42 \\
\hline Propionate & 29.4 & 164 & 1.46 & 33.8 & 369 & 0.58 \\
\hline Butyrate & 25.5 & 175 & 1.36 & 39.1 & 390 & 0.70 \\
\hline Pentanoate & 20.6 & 185 & 1.16 & 42.4 & 405 & 0.79 \\
\hline Hexanoate & 16.9 & 195 & 1.00 & 51.0 & 425 & 1.00 \\
\hline
\end{tabular}



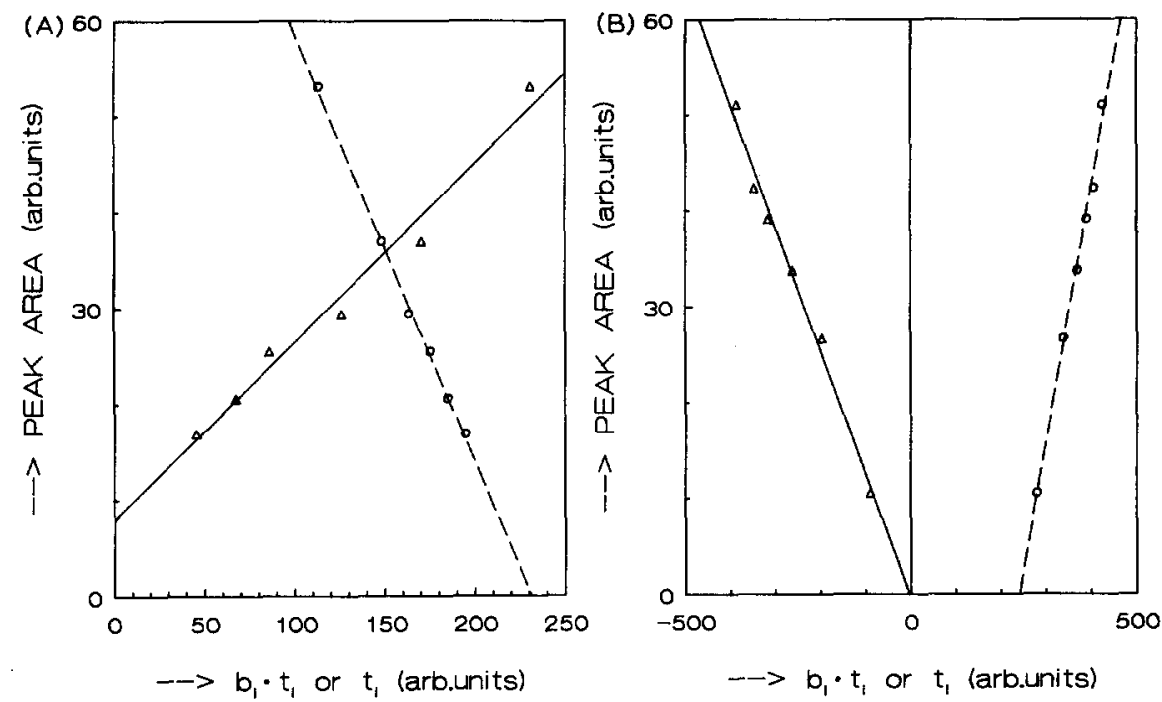

Fig. 2. Relationship between measured peak area [1] and $b_{t} t_{i}$ (solid line) and $t_{i}$ (dashed line) for the electrolyte system (A) $0.01 \mathrm{M}$ MES adjusted to $\mathrm{pH}$ of 6 by adding histidine and (B) $0.005 \mathrm{M} \mathrm{HCl}$ adjusted to $\mathrm{pH} 7.1$ by adding Tris. The sample consisted of a mixture of formate, acetate, propionate, butyrate, pentanoate and hexanoate. Applying the correction factor $b_{i}$ a linear relationship passing through the origin is obtained according to eqn. 4.

although for a fairly small mobility range (the arrows indicate broadly the mobility range of formate to hexanoate) it is nearly linear.

Table I gives the measured peak areas and migration times according to Huang et al. [1] and the calculated ratios $c_{i} / c_{\mathrm{st}}$, with hexanoate considered as a standard (st), using the equation $c_{i}=c_{\mathrm{st}} A_{i} t_{i} / A_{\mathrm{st}} t_{\mathrm{st}}$ as used by Huang et al. [1]. It can be concluded from Table I that this equation cannot be used in general, as the quotients have to be unity for an equimolar sample composition.

In Fig. $2 \mathrm{~A}$ and $\mathrm{B}$ the relationships between peak area, as measured by Huang $e t$ $a l$. [1], and the calculated $b_{i} t_{i}$ or $t_{i}$ are given. We applied eqn. 4 (and not eqn. 5) because we did not know if the EOF was fully suppressed by the addition of tetradecyltrimethyl ammonium bromide (TTAB). It can be clearly seen that the linear relationship between temporal peak area and migration time (dashed line), as measured by Huang $e t$ al. changes into a linear relationship nearly passing through the origin on applying the correction factor $b_{i}$ (solid line), as expected from theory. The results in Fig. 2B are better than those in Fig. 2A (large intercept on the ordinate) because the accuracy of the effective mobility 2-(N-morpholino)ethanesulphonic acid (MES) is very critical to the calculated value of $b_{i}$. In the calculation of the factor $b_{i}$ the mobilities have been corrected according to the Debye-Hückel-Onsager theory.

It is obvious that a relationship between peak area $A_{i}$ and retention time $t_{i}$, not linear and not passing through the origin, is not practical to be used for an internal standard, in contrast with the use of the relationship between peak area $A_{i}$ and the product $b_{i} t_{i}$. 
For a UV detector the measured absorbance A will be

$$
A=\varepsilon c l
$$

where $\varepsilon$ is the molar absorption coefficient $(1 / \mathrm{mol} \cdot \mathrm{cm})$ and $l$ is the effective path length in the detector $(\mathrm{cm})$. For the carrier electrolyte this means

$$
A^{\mathrm{C}}=\left(\varepsilon_{\mathrm{A}}+\varepsilon_{\mathrm{B}}\right) c_{\mathrm{A}}^{\mathrm{C}} l
$$

For a sample zone the absorbance will be

$$
A^{\mathrm{S}}=\left(\varepsilon_{\mathrm{A}}+\varepsilon_{\mathrm{B}}\right) c_{\mathrm{A}}^{\mathrm{S}} l+\left(\varepsilon_{\mathrm{B}}+\varepsilon_{i}\right) c_{i}^{\mathrm{S}} l
$$

The UV signal of a sample zone, using eqn. 2 , will be

$$
A=A^{\mathrm{C}}-A^{\mathrm{S}}=C_{i}^{\mathrm{S}}\left[\left(\varepsilon_{\mathrm{A}}+\varepsilon_{\mathrm{B}}\right) k_{i}-\left(\varepsilon_{i}+\varepsilon_{\mathrm{B}}\right)\right]
$$

For non-UV-absorbing counter ions and sample ions, applying indirect UV detection with UV-absorbing co-ions, the UV signal is proportional to $c_{i} k_{i}$.

Analogously to conductivity detection, the spatial peak area will be proportional to $k_{i} Q_{\mathrm{inj}}$ and the measured peak area $A_{i}$ on a temporal basis to $k_{i} Q_{\mathrm{inj}} t_{i}$. Further, the expression $A_{i} / k_{i} t_{i}$ has to be a constant in a given electrolyte system for all components at an equimolar sample composition.

\section{EXPERIMENTAL}

\section{Instrumentation}

For all quantitative experiments with a conductivity detector we used a laboratory-built capillary electrophoresis system with an on-column conductivity detector as described previously [4]. As the apparatus is a closed system, the EOF is fully suppressed. The sampling takes place into a broadened part of the capillary tube $(0.55$ $\mathrm{mm}$ I.D.) connected with two feeders $(0.4 \mathrm{~mm}$ diameter), perpendicular to the capillary tube. A constant d.c. power supply with a maximum potential of $20 \mathrm{kV}$ was used. Peak areas were determined using the integration program CAESAR. The detector electronics were connected with an IBM XT PC via a LabMaster (Scientific Solutions, Solon, USA).

For all quantitative CZE experiments with a UV detector we used the P/ACE System 2000 HPCE (Beckman, Palo Alto, CA, USA) applying UV detection at 254 $\mathrm{nm}$. All experiments were carried out at $25^{\circ} \mathrm{C}$ using an original Beckman capillary of $57 \mathrm{~cm}$, with a distance between injection and detection of $50 \mathrm{~cm}$ and an I.D. of $75 \mu \mathrm{m}$.

For all zone electrophoretic separations the injection took place at the inlet side. In the anionic mode the cathode was placed at the inlet and the anode at the outlet side, and vice versa for the cationic mode.

\section{Reagents and samples}

All chemicals were of analytical-reagent grade. Before preparing the sample solutions, all chemicals were dried at $105^{\circ} \mathrm{C}$. 
TABLE II

EFFECTIVE MOBILITIES $-m_{i} \cdot 10^{-5}\left(\mathrm{~cm}^{2} / \mathrm{V} \cdot \mathrm{s}\right)$, CALCULATED FACTORS $b_{i}$ (ARBITRARY UNITS), MEASURED PEAK AREAS $A_{i}$ (ARBITRARY UNITS) AND CALCULATED VALUES OF $K\left(=A_{i} m_{i} / b_{i}\right)$ FOR DIFFERENT BACKGROUND ELECTROLYTES

\begin{tabular}{|c|c|c|c|c|}
\hline Component & $m_{i}$ & $b_{i}$ & $A_{i}$ & $K$ \\
\hline \multicolumn{5}{|c|}{$0.01 M M E S+$ imidazole ( $p H 7)$} \\
\hline Chloride & 74.45 & 79.30 & 218.47 & 205.1 \\
\hline Chlorate & 62.61 & 65.00 & 209.08 & 201.4 \\
\hline Fluoride & 53.22 & 52.75 & 201.93 & 203.7 \\
\hline Formate & 52.43 & 51.68 & 200.34 & 203.3 \\
\hline Acetate & 38.54 & 30.50 & 163.76 & 206.9 \\
\hline Propionate & 33.36 & 20.94 & 136.66 & 217.7 \\
\hline Benzoate & 29.93 & 13.75 & 112.66 & 245.2 \\
\hline \multicolumn{5}{|c|}{$0.01 \mathrm{M}$ acetic acid + imidazole $(p H 7)$} \\
\hline Chloride & 74.17 & 56.84 & 122.71 & 160.1 \\
\hline Chlorate & 62.35 & 40.93 & 103.74 & 158.0 \\
\hline Fluoride & 52.97 & 26.87 & 78.77 & 155.3 \\
\hline Formate & 52.18 & 25.62 & 72.51 & 147.7 \\
\hline Propionate & 33.13 & -12.19 & -53.70 & 145.9 \\
\hline Benzoate & 29.71 & -21.61 & -100.35 & 137.9 \\
\hline \multicolumn{5}{|c|}{$0.01 \mathrm{M} \mathrm{HCl}+$ imidazole $(\mathrm{pH} 7)$} \\
\hline Chlorate & 62.35 & -20.14 & -31.74 & 98.3 \\
\hline Fluoride & 52.97 & -38.88 & -68.82 & 93.8 \\
\hline Formate & 52.18 & -40.60 & -72.95 & 93.8 \\
\hline Acetate & 38.31 & -77.67 & -180.98 & 89.3 \\
\hline Propionate & 33.13 & -96.60 & -253.93 & 87.1 \\
\hline Benzoate & 29.71 & -111.75 & -316.45 & 84.2 \\
\hline
\end{tabular}

\section{RESULTS AND DISCUSSION}

In order to check the relationship between temporal peak area and mobilities for both conductivity (eqn. 5) and indirect UV detection (eqn. 9), we measured the temporal peak area with conductivity detection and indirect UV detection, in both the anionic and cationic modes.

In Table II, the effective mobilities, $m_{i}$, calculated factors, $b_{i}$, temporal peak areas, $A_{i}$ (measured with a closed CZE apparatus with an on-line conductivity detector [4]), and calculated values of $K$ are given. The factors $K\left(=A_{i} m_{i} / b_{i}\right)$ are virtually constant in the three different electrolyte systems, although a disadvantage of the sample injection used in our apparatus is that although linear calibration graphs are obtained for both isotachophoretic and CZE experiments, the effective injection volumes for the different components are not completely identical [4], and moreover the separation power of the apparatus used was too small to separate the whole sample mixture in a single experiment. Of course the values of the factors $K$ for the different systems are different due to different circumstances. The three different electrolyte systems consisted of the co-ions MES, acetate and chloride at a $\mathrm{pH}$ of 7 adjusted by adding imidazole (anionic mode, constant electric current $10 \mu \mathrm{A}$ ). The sample components were chloride, chlorate, fluoride, formate, acetate, propionate and benzoate at a concentration of $5 \cdot 10^{-4} \mathrm{M}$. 

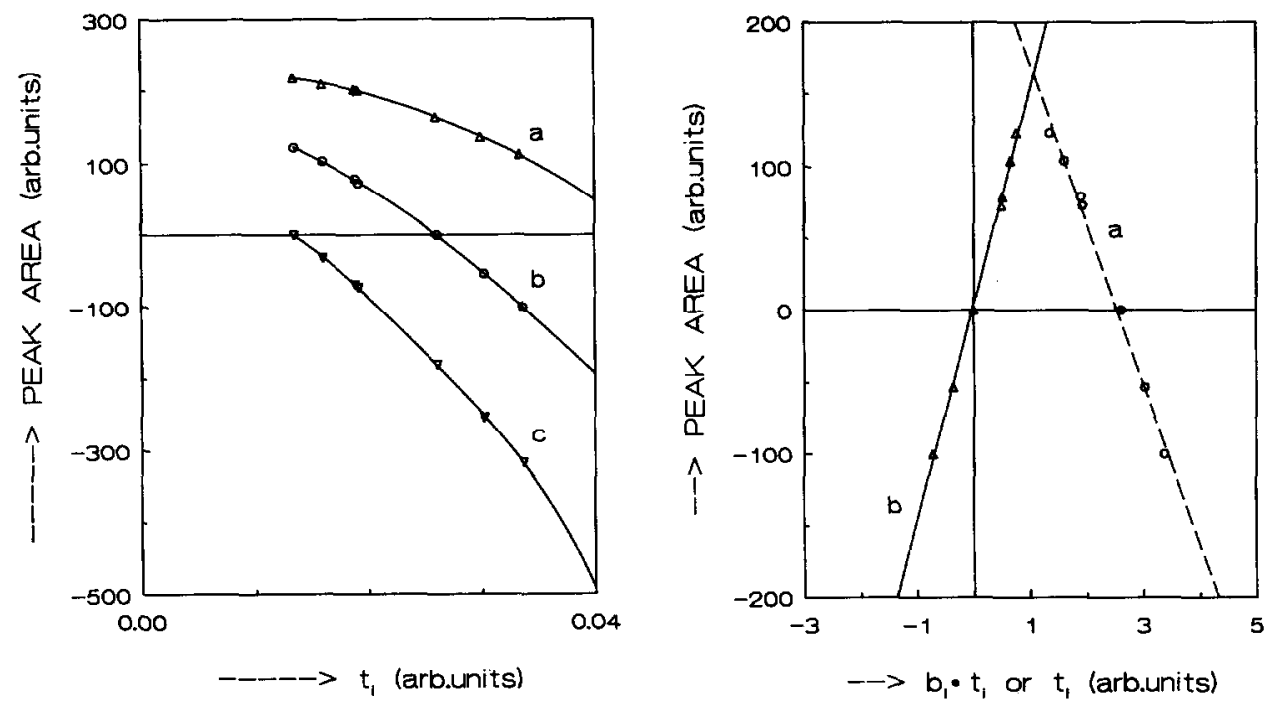

Fig. 3. Relationship between measured peak area and $t_{i}$ for conductivity detection in a closed system, for three different electrolyte systems. The sign of the peak area changes at an effective mobility equal to that of the co-ion, confirming the theory (see Table II for data). Background electrolyte: (a) MES, (b) acetic acid and (c) hydrochloric acid, all at pH 7 adjusted by adding imidazole.

Fig. 4. Relationship between measured peak area and (a) $t_{i}$ and (b) $b_{i} t_{i}$ for the electrolyte system $0.01 M$ acetic acid adjusted to $\mathrm{pH} 7$ by adding imidazole. The sample consisted of a mixture of chloride, chlorate, fluoride, acetate, propionate and benzoate $\left(5 \cdot 10^{-4} M\right)$. It can be clearly seen that the relationship between peak area and $t_{i}$ (dashed line) changes to a linear relationship passing through the origin if the correction factor $b_{i}$ is used (solid line).

In Fig. 3 the measured peak areas in Table II are given as a function of time. The similarity with Fig. 1 is obvious.

In Fig. 4 the measured peak areas of one of the electrolyte systems in Table II are given as a function of both (a) the migration time $t_{i}$ and (b) $b_{i} t_{i}$. It can be clearly seen that relationship (a) changes into (b), a linear relationship passing through the origin.

To check the relationship between peak area and mobilities for indirect UV detection with non-UV-absorbing components and counter ions, experiments were carried out in both the anionic and cationic modes. In the anionic mode we used three background electrolytes, $0.01 M$ benzoic acid, $0.01 M$ nicotinic acid and $0.01 M$ sulphosalicylic acid adjusted to $\mathrm{pH} 8$ by adding Tris [tris(hydroxymethyl)aminomethane]. The sample mixture consisted of chloride, chlorate, fluoride, acetate, propionate and MES $\left(5 \cdot 10^{-4} M\right)$, applying pressure injection times of 5,10 and $15 \mathrm{~s}$. All experiments were carried out with a constant voltage of $25 \mathrm{kV}$. In order to supress the EOF for the greater part, $0.05 \%$ methylhydroxyethylcellulose (MHEC) was added to all solutions.

In Table III the calculated effective mobilities and calculated factors $k_{i}$, the measured migration times $t_{i}$, measured peak areas $A_{i}$ and calculated values of $K$ $\left(=A_{i} / k_{i} t_{i}\right)$ are given. The factor $K$ should be a constant for all components in the same 


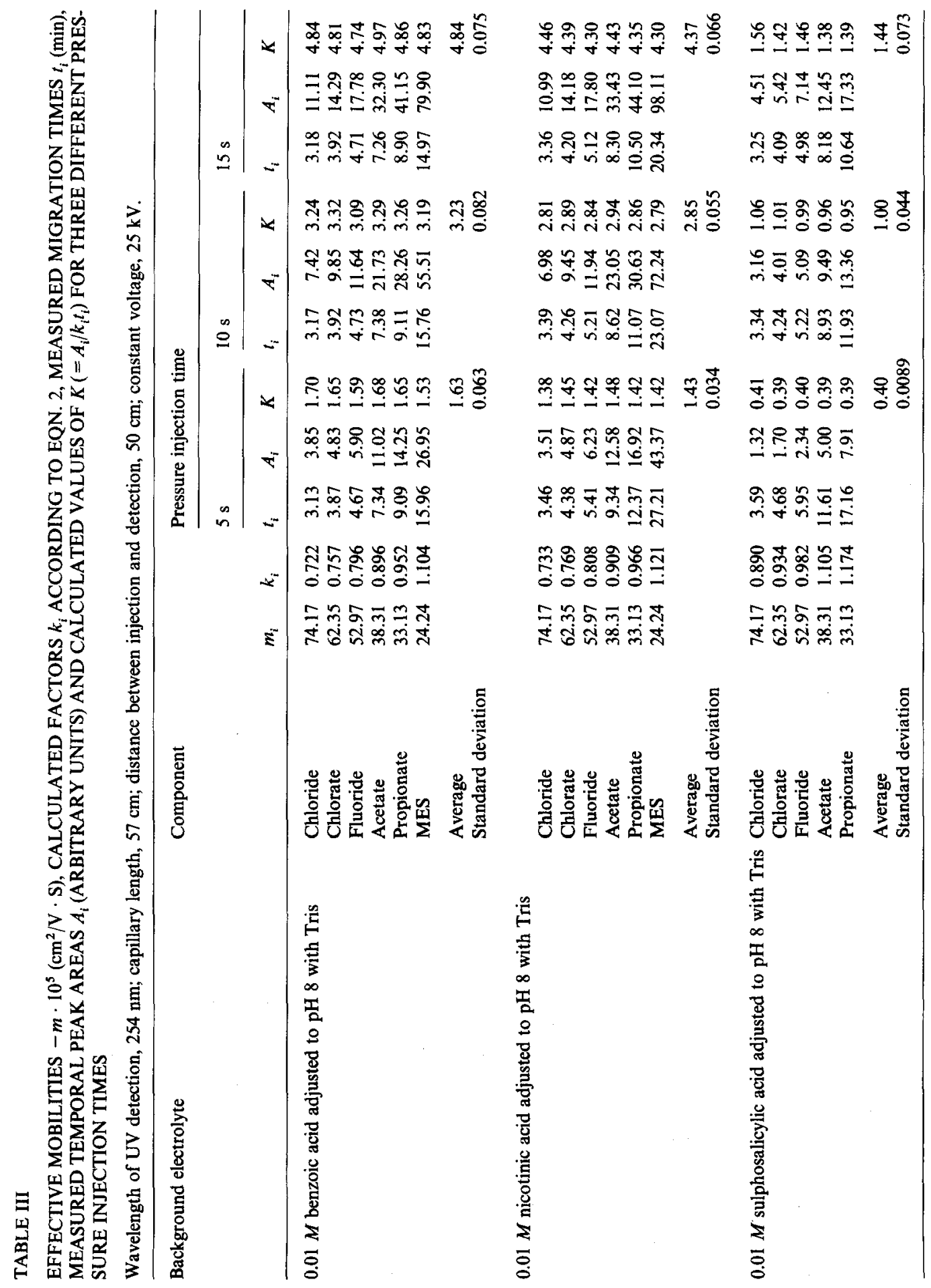




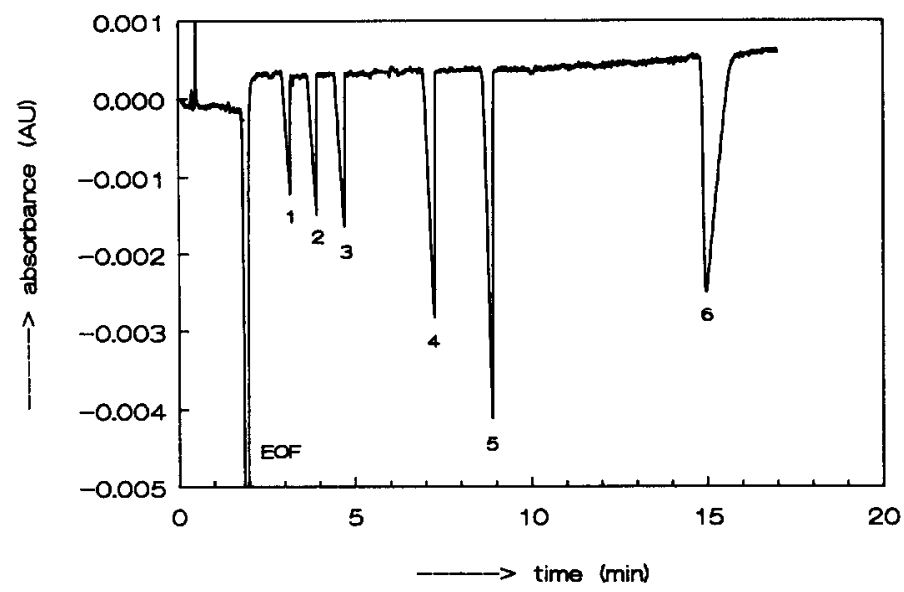

Fig. 5. Electropherogram for the separation of (1) chloride, (2) chlorate, (3) fluoride, (4) acetate, (5) propionate and (6) MES in the indirect UV mode $\left(5 \cdot 10^{-4} M\right.$, pressurc injection time 15 s). Carrier electrolyte, $0.01 M$ benzoic acid adjusted to $\mathrm{pH} 8$ by adding Tris; wavelength, $254 \mathrm{~nm}$; anionic mode, applied voltage $25 \mathrm{kV}$.

\section{TABLE IV}

CALCULATED EFFECTIVE MOBILITIES $-m_{i} \cdot 10^{5}\left(\mathrm{~cm}^{2} / \mathrm{V} \cdot \mathrm{s}\right)$, CALCULATED FACTORS $k_{i}$ ACCORDING TO EQN. 2, MEASURED MIGRATION TIMES $t_{i}(\mathrm{~min})$, MEASURED TEMPORAL PEAK AREAS $A_{i}$ (ARBITRARY UNITS) AND CALCULATED VALUES OF $K\left(=A_{i} / k_{i} t_{i}\right)$ FOR THREE DIFFERENT PRESSURE INJECTION TIMES

\begin{tabular}{|c|c|c|c|c|c|c|}
\hline Pressure injection time (s) & Component & $m_{i}$ & $k_{i}$ & $t_{i}$ & $A_{i}$ & $K$ \\
\hline \multirow[t]{7}{*}{5} & Hexanoate & $26.09(0.115)$ & $1.064(0.002)$ & $4.69(0.017)$ & $11.54(0.181)$ & $2.31(0.038)$ \\
\hline & Pentanoate & $27.65(0.112)$ & $1.035(0.002)$ & $4.88(0.015)$ & $11.72(0.181)$ & $2.32(0.035)$ \\
\hline & Butanoate & $29.51(0.119)$ & $1.003(0.002)$ & $5.12(0.019)$ & $12.20(0.089)$ & $2.37(0.019)$ \\
\hline & Propionate & $32.58(0.099)$ & $0.959(0.001)$ & $5.58(0.021)$ & $13.34(0.200)$ & $2.49(0.037)$ \\
\hline & Acetate & $37.31(0.102)$ & $0.905(0.001)$ & $6.49(0.029)$ & $15.12(0.133)$ & $2.57(0.025)$ \\
\hline & Formate & $51.67(0.112)$ & $0.803(0.001)$ & $12.71(0.127)$ & $24.01(0.625)$ & $2.35(0.054)$ \\
\hline & Average & & & & & $2.40(0.105)$ \\
\hline \multirow[t]{7}{*}{10} & Hexanoate & $26.50(0.050)$ & $1.056(0.001)$ & $4.61(0.032)$ & $23.53(0.262)$ & $4.83(0.074)$ \\
\hline & Pentanoate & $28.05(0.035)$ & $1.028(0.001)$ & $4.79(0.032)$ & $23.97(0.292)$ & $4.87(0.076)$ \\
\hline & Butanoate & $29.73(0.068)$ & $1.000(0.001)$ & $5.00(0.039)$ & $24.94(0.306)$ & $4.99(0.080)$ \\
\hline & Propionate & $32.59(0.064)$ & $0.959(0.001)$ & $5.41(0.046)$ & $26.86(0.374)$ & $5.18(0.100)$ \\
\hline & Acetate & $37.21(0.064)$ & $0.906(0.001)$ & $6.23(0.060)$ & $29.96(0.370)$ & $5.31(0.078)$ \\
\hline & Formate & $51.38(0.082)$ & $0.804(0.000)$ & $11.64(0.224)$ & $48.20(0.731)$ & $5.15(0.162)$ \\
\hline & Average & & & & & $5.06(0.189)$ \\
\hline \multirow[t]{7}{*}{15} & Hexanoate & $26.76(0.109)$ & $1.051(0.002)$ & $4.63(0.010)$ & $35.61(1.480)$ & $7.31(0.302)$ \\
\hline & Pentanoate & $28.28(0.088)$ & $1.024(0.002)$ & $4.81(0.010)$ & $36.08(1.004)$ & $7.33(0.203)$ \\
\hline & Butanoate & $29.84(0.092)$ & $0.998(0.001)$ & $5.01(0.013)$ & $37.49(0.985)$ & $7.50(0.190)$ \\
\hline & Propionate & $32.56(0.113)$ & $0.959(0.001)$ & $5.40(0.013)$ & $40.02(0.760)$ & $7.73(0.141)$ \\
\hline & Acetate & $37.17(0.116)$ & $0.907(0.001)$ & $6.21(0.017)$ & $44.90(1.423)$ & $7.97(0.250)$ \\
\hline & Formate & $51.54(0.097)$ & $0.804(0.001)$ & $11.71(0.083)$ & $72.40(3.469)$ & $7.69(0.323)$ \\
\hline & Average & & & & & $7.59(0.256)$ \\
\hline
\end{tabular}




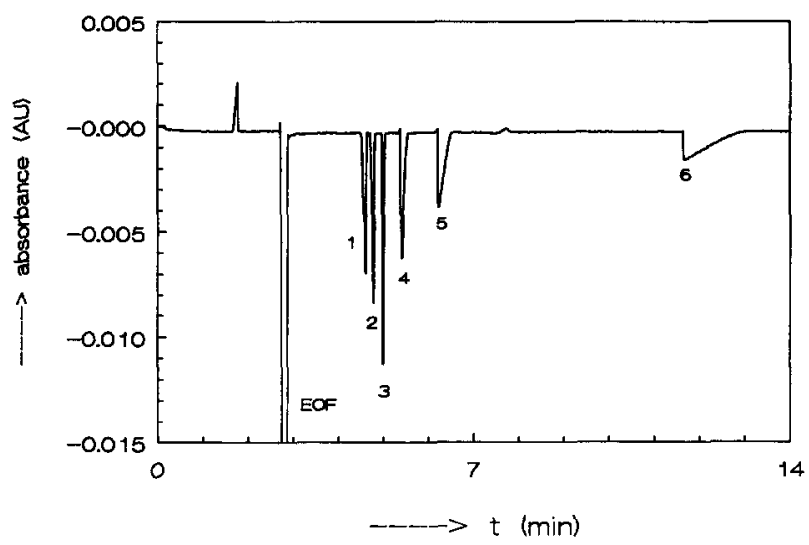

Fig. 6. Electropherogram for the separation of (1) hexanoate, (2) pentanoate, (3) butanoate, (4) propionate, (5) acetate and (6) formate in the indirect UV mode $\left(5 \cdot 10^{-4} M\right.$, pressure injection time $\left.10 \mathrm{~s}\right)$. Carrier electrolyte, $0.01 M$ benzoic acid adjusted to $\mathrm{pH} 8.5$ by adding Tris; wavelength, $254 \mathrm{~nm}$; cationic mode, applied voltage $25 \mathrm{kV}$.

carrier electrolyte. It can be concluded from Table III that the factor $K$ is indeed a constant for all components and is linearly related to the amount of the components injected.

Fig. 5 gives an example of the separation of a mixture (in the anionic mode, pressure injection time $15 \mathrm{~s}$ ) with indirect UV detection. The carrier electrolyte was $0.01 M$ benzoic acid at $\mathrm{pH}$ 8. The sample consisted of (1) chloride, (2) chlorate, (3) fluoride, (4) acetate, (5) propionate and (6) MES at a concentration of $5 \cdot 10^{-4} M$. In order to obtain an impression of the velocity of the EOF (remember that the EOF is suppressed for the greater part by the addition of $0.05 \%$ MHEC to all solutions), we created an EOF peak directed from outlet to inlet by injecting water at the outlet side by electromigration injection at $10 \mathrm{kV}$ for $5 \mathrm{~s}$ (the length from injection to detection is only $7 \mathrm{~cm}$ for this EOF marker; $m_{\mathrm{EOF}}$ is about $14 \cdot 10^{-5} \mathrm{~cm}^{2} / \mathrm{V} \cdot \mathrm{s}$; without MHEC $m_{\mathrm{EOF}}$ is about $67 \cdot 10^{-5} \mathrm{~cm}^{2} / \mathrm{V} \cdot \mathrm{s}$ ). Note the fronting and tailing shapes of the peaks with high and low effective mobilities, respectively.

In the cationic mode we applied an electrolyte system consisting of $0.01 M$ benzoic acid adjusted to $\mathrm{pH} 8.5$ by adding Tris. The applied voltage was $25 \mathrm{kV}$. The sample consisted of formate, acetate, propionate, butanoate, pentanoate and hexanoate at a concentration of $5 \cdot 10^{-4} M$, applying pressure injection times of 5,10 and $15 \mathrm{~s}$. In Table IV the effective mobilities and calculated factors $k_{i}$, the measured migration times $t_{i}$, measured peak area $A_{i}$ and calculated factors $K\left(=A_{i} / k_{i} l_{i}\right)$ are given. The effective mobilities of the components are calculated from the migration times of the EOF and of the components as described previously [5].

In order to study the reproducibility of the method, all experiments were carried out five times and the average values are given in Table IV. Standard deviations are given in parentheses. It can be concluded from these data that the reproducibility is good for the migration times and the calculated effective mobilities and factors $k_{i}$. The reproducibility of $K$ values is poorer (standard deviation $c a .1-2 \%$ ) owing to the 
inaccuracy of the measured peak areas, possibly caused by the injection method and/or inaccuracy of the peak-area determination.

Fig. 6 gives an example of the separation of the mixture in Table IV (in the cationic mode, pressure injection time $10 \mathrm{~s}$ ) in the indirect $\mathrm{UV}$ mode. The carrier electrolyte was $0.01 \mathrm{M}$ benzoic acid at $\mathrm{pH} 8.5$ adjusted by adding Tris. The strong tailing effect for formate due to the absence of a self-correcting effect of the zones in CZE can be clearly seen.

\section{CONCLUSIONS}

For conductivity and indirect UV detection (for non-UV-absorbing components, applying a non-UV-absorbing counter ion and a UV-absorbing co-ion) there is a defined relationship between measured temporal peak areas and effective mobilities, independent of the kind of ionic species. Data measured for several components in several electrolyte systems confirmed the derived relationship.

The relationship between temporal peak area and the product of a correction factor $\left(b_{i}\right.$ for conductivity detection and $k_{i}$ for indirect UV detection) and migration time $t_{i}$ is linear, passing through the origin. Applying an internal standard, this relationship can be used in quantitative CZE analysis with calibration graphs being superfluous.

\section{ACKNOWLEDGEMENTS}

The authors express their gratitude to the State Institute for Quality Control for Agricultural Products (RIKILT, Netherlands) for financial support of this investigation and to Mr. B. J. Wanders for placing at their disposal the CAESAR data acquisition and analysis program.

\section{REFERENCES}

1 X. Huang, J. A. Luckey, M. J. Gordon and R. N. Zare, Anal. Chem., 61 (1989) 766.

2 F. E. P. Mikkers, Thesis, University of Technology, Eindhoven, 1980.

2 X. Huang, W. F. Coleman and R. N. Zare, J. Chromatogr., 480 (1989) 95.

4 Th. P. E. M. Verheggen, J. L. Beckers and F. M. Everaerts, J. Chromatogr., 452 (1988) 615.

5 J. L. Beckers, F. M. Everaerts and M. T. Ackermans, J. Chromatogr., 537 (1991) 407. 